УДК 338.025

ББК 65.29

$10.17213 / 2075-2067-2021-4-172-180$

\title{
ВНЕДРЕНИЕ ЦИФРОВЫХ ТЕХНОЛОГИЙ НА РЕГИОНАЛЬНОМ УРОВНЕ
}

\author{
(C) 2021 г. E. В. Рожков
}

Уральский государственный экономический университет, г. Екатеринбурд, Россия

Целью исследования является выявление перспектив внедрения циифровых технологий на уровне региона.

Методологическую базу исследования представляют иифровые критерии, создающие технологическую основу для ичирровизации сектора государственного управления. Оценки уровня циифровизации управления связаны со следующими элементами: определение стартовых понятий информации, цифровизации и циирровой трансформации государственного управления; определение требований к поиску правовых ограничений и возможностей ичифровизаџии госуправления.

Результаты исследования. Одним из основных явлений внедрения изифровых технологий является сглаживание имеюшихся неравенств в виде доступности интернета в региональной столице по сравнению с периферией (небольшие населенные пункты на границе региона, в основном расположенные в местности, окруженной лесами).

Перспективу исследования составляет анализ предложенных региональными органами власти привилегий для бизнеса, желающего заниматься IT-экономикой, и возможности положительных последствий от привлечения инвестищий в IT-сектор.

Ключевые слова: иүифровизаџия; регион; экономика; инвестиџии; реализаџия; проектыл.

\section{DIGITAL ADOPTION AT THE REGIONAL LEVEL}

\section{(C) 2021 E. V. Rozhkov}

\section{Ural State University of Economics, Yekaterinburg, Russia}

The aim of the study is to identify the prospects for the introduction of digital technologies at the regional level.

The methodological basis of the study is presented by digital criteria that create a technological basis for digitalization of the public administration sector. Estimates of the level of digitalization of management are associated with the following elements: definition of starting concepts of information, digitalization and digital transformation of public administration; identification of requirements for finding legal restrictions and opportunities for digitalization of public administration.

The results of the study. One of the main phenomena of the introduction of digital technologies is the smoothing of existing inequalities in the form of Internet accessibility in the regional capital compared to the periphery (not large settlements on the border of the region, mainly located in an area surrounded by forests). 
The perspective of the study is an analysis of the privileges proposed by regional authorities for businesses wishing to engage in the IT economy and the possibility of positive consequences from attracting investments in the IT sector.

Key words: digitalization; region; economy; investments; implementation; projects.

Введение. Затраты на реализацию мероприятий федерального проекта «Цифровой регион», который включен в национальную программу «Цифровая экономика», составят 247,5 млрд. руб. (до 2024 года). Из этой суммы бюджеты регионов составляют 177,3 млрд. руб.

Развитие потенциала реального сектора возможно в результате реализации передовых достижений шестого технологического уклада и концепции «Индустрия 4.0», соответствующих технологическим, экономическим и геополитическим угрозам и вызовам [16], а современное развитие экономики многие ученые называют этапом трансформации [30].

Необходимо отметить, что в достаточно большом количестве работ по теме цифровизации авторы говорят о различиях в доходах на распространение ИКТ [1-5, 8].

Теоретико-методологическая актуальность статьи заключается в выявлении экономической необходимости внедрения цифровых технологий на уровне региона во всех сферах деятельности.

Цель статьи - выявить новые связи между малым и средним бизнесом и органами власти по внедрению цифровизации в регионе.

Сегодня цифровые технологии широко используются в зарубежных странах. Так, например, в Германии применение их в государственно-управленческой сфере показывает, что использование программного обеспечения и автоматизированных информационных систем способствует сокращению государственных расходов, увеличивает скорость предоставления услуг населению и т.д. $[6,7,9]$; в Великобритании при формировании государственной политики используется платформа «Predictive», способная проводить эксперименты в режиме реального времени, и т.д. [10].

Стратегией развития информационного общества в России до 2030 года предложен комплекс мер, направленных на развитие цифрового общества в России [20].
В России цели, которые поставлены перед Правительством по развитию экономики, направлены на инновационную модель развития и реализацию единой государственной информационной политики с необходимостью создания соответствующего инновационного климата и инновационной инфраструктурной системы [28].

Соответственно, о развитии цифровой экономики все больше стали говорить не только на государственном, но и на региональном уровне. Цифровая экономика новый тип экономики, основанный на современных информационно-коммуникационных технологиях и современной информационной сети как носителе для реализации производства, обмена и потребления ресурсов через информационную сеть [31].

Обзор научно-исследовательской литературы. Внедрение цифровых технологий в экономике изучалось как зарубежными авторами (M. Billon, K. Bagchi, M.D. Chinn, S. Dasgupta), так и российскими: М. А. Жуковой, Н. Х. Норалиевым, А.С. Сибиряевым, Е.А. Полиной и другими.

Можно считать, что к объектам цифровизации экономисты относят продукты, создающиеся на основе использования цифровых технологий, и процессы, базирующиеся на использовании цифровых технологий [18]. Функционирование систем в реальном времени будет обеспечиваться за счет подключенности с опорой на «данные». В производственносбытовых цепочках будет гарантироваться прослеживаемость и координация создания оптимальной модели управления [21, 25].

М.Н. Калина и М.М. Куликов определили, что наиболее распространенными ITтехнологиями являются использование промышленных роботов (44,5\% организаций), применение технологии компьютерного инжиниринга (41,1\% предприятий), а также цифровой сбор, обработка и анализ больших массивов данных (36\% предприятий) [19]. 
По мнению А.А. Урасовой и Д.А. Баландина, одним из актуальных вопросов управления отраслями экономики для регионов на сегодняшний день является выдвижение задач по нахождению точек роста и изыскания резервов для интенсивного развития [29].

В.Л. Симонова и другие считают, что цифровая трансформация бизнеса - это полное внедрение цифровых технологий в их деятельность. И цифровизация бизнеса показывает, что развивающиеся цифровые компании сосредоточены на интеграции цифровых технологий [27].

А.Ю. Веретенникова и К.М. Козинская выявили, что развитие социального предпринимательства тесно связано с ускорением социально-экономических и технологических процессов, вызванных повышением скорости обмена данными и цифровой трансформацией в целом [12].

Изменение информационного пространства в виде феномена цифровой экономики способствует формированию новой инфраструктуры [11].

Методология исследования. Методический подход по проведению процедуры оценивания реализации цифровых технологий в регионе содержит следующие этапы:

1) оценка сопряженности и согласованности между количественными показателями стратегических целей, приоритетов, задач и параметров государственных программ, т.е. качества цифровизации процессов исполнения;

2) оценка сбалансированности долгосрочных и среднесрочных приоритетов по критерию сохранения преемственности в «коридоре» стратегических индикаторов [15].
В основу методики должны одновременно закладываться как цифровые критерии, создающие технологическую основу для цифровизации сектора государственного управления, так и нецифровые, которые формируют оптимальные основы для цифровизации государственного управления [26].

Выявляемые ограничения при оценке уровня цифровизации управления связаны со следующими элементами: определение стартовых понятий информации, цифровизации и т.д. [32].

Результаты исследования. Инновационное развитие регионов - это приоритетная задача формирования конкурентоспособной и устойчивой экономики, для реализации которой разработаны такие государственные программы, как новое качество жизни, инновационное развитие и т.д. [22].

Так, например, в Пермском крае под руководством региона была разработана и утверждена Концепция развития цифровой экономики (далее - Концепция развития), в соответствии с которой вплоть до 2024 года должны произойти существенные изменения в IT-отрасли (табл. 1).

Как видно по данным, представленным в таблице 1, доля IT-сектора в региональной экономике должна увеличиться в 2 раза, а численность сотрудников, работающих в компаниях в области информации и связи, - увеличиться на 6000 человек, что составит рост на $37,5 \%$ от уже работающих 16000 сотрудников.

Кроме того, в 2021 году между руководством региона и ПАО «МегаФон» было подписано Положение, предусматривающее совместную реализацию проектов по развитию цифровых сервисов и телеком-инфраструк-

Таблица 1

\section{Концепция развития цифровой экономики Пермского края}

\begin{tabular}{|c|l|l|c|c|}
\hline \multirow{2}{*}{$№$} & \multicolumn{1}{|c|}{$\begin{array}{c}\text { Целевой } \\
\text { показатель }\end{array}$} & \multicolumn{1}{|c|}{ Источник } & \multicolumn{2}{|c|}{ Год } \\
\cline { 3 - 5 } 1 & $\begin{array}{l}\text { Доля ІТ-сектора в } \\
\text { экономике }\end{array}$ & $\begin{array}{l}\text { В области информации и связи к показателю } \\
\text { «Отружено товаров собственного производства, } \\
\text { выполнено работ и услуг собственными силами» }\end{array}$ & 2,1 & 4 \\
\hline 2 & $\begin{array}{l}\text { Численность заня- } \\
\text { тых в ІТ-секторе }\end{array}$ & $\begin{array}{l}\text { Численность сотрудников в организациях в об- } \\
\text { ласти информации и связи }\end{array}$ & 16000 & 22000 \\
\hline
\end{tabular}


туры в рамках национальной программы «Цифровая экономика». Также Положение предусматривает цикл мероприятий, направленных на рост скорости доступа пользователей к электронным государственным ресурсам и муниципальным услугам. Особенно это важно во времена объявления ограничений передвижения при инфекционных заболеваниях населения (COVID-19), кроме того, это сглаживает имеющиеся неравенства в виде доступности интернета в региональной столице по сравнению с периферией (небольшие населенные пункты на границе региона, в основном расположенные в местности, окруженной лесами).

Обсуждение результатов исследования. В настоящее время в нашей стране утверждена упрощенная процедура регистрации ITкомпаний, позволяющая малому и среднему бизнесу войти в IT-сектор экономики и занять имеющуюся «нишу» по реализации современных потребностей общества и государства в своем развитии. На уровне Пермского края, например, Концепцией развития для этого предусмотрены налоговые льготы для компаний IT-отрасли $(1,1 \%$ - налог на имущество и $0 \%$ - налог для собственников имущества IT-технопарка), что способствует привлечению инвесторов в новый, развивающийся сектор экономики, а это вполне может соответствовать стремлению развития страны в целях инновационной политики [13].

Также необходимо учитывать, что внедрение цифровых технологий способствует ускорению инновационных процессов [14]. Особенно это заметно на муниципальном уровне. Достаточно лишь небольшого увеличения расходной части бюджета на цифровые технологии и на муниципальном уровне, уже можно будет максимально реализовать интеграцию и централизацию обработки информации и принятия управленческих решений на основе единой платформы с учётом использования координирующего механизма рынка, повышения экономической эффективности объекта инфраструктуры [17].

Также следует отметить, что до 2024 года необходимо решить следующие задачи: формирование информационной инфраструктуры, увеличение рабочих мощностей серверного оборудования и объемов систем хра- нения данных. В результате работы проекта «Умный город» в муниципальных образованиях должна создаваться актуальная информация для обеспечения управления муниципальной собственностью [23].

Кроме того, необходимо разработать и модернизировать цифровую инфраструктуру, внедрить цифровые практики во всех ключевых сферах экономики, трансформировать систему мониторинга цифровизации социально-экономических процессов на уровне региона [24].

Заключение. Количество информации, которую необходимо переработать для выработки эффективных управленческих решений, настолько велико, что оно давно превысило человеческие возможности. Именно трудности управления объемом информации обусловили широкое использование электронно-вычислительной техники, разработку автоматизированных систем управления, что потребовало создания нового математического аппарата и экономико-математических методов.

Внедрение цифровых технологий в повседневную жизнь людей ощущается как необходимость, и наблюдение за их внедрением вполне осуществимо в условиях четкого и постоянного контроля со стороны региональных органов власти, а также при соответствующем финансировании как из регионального бюджета, так и из федерального.

\section{Литература}

1. Bagchi K. Factors contributing to Global Digital Divide: Some empirical results // Journal of Global information Technology Management. - 2005. - №8 (3). - Pp. 47-65.

2. Billon M., Marco R., Lera-Lopez F. Disparities in ICT adoption: A multidimensional approach to study the cross-country digital // Telecommunications Policy. — 2019. — №33(10-11). Pp. 596-610.

3. Chinn M.D., Fairlie R.W. The Determinants of the Global Digital Divide: A CrossCountry Analysis of Computer and Internet Penetration // Oxford Economic Papers. New Series. - 2007. — Vol. 59. — №1. - Pp. 16-44.

4. Dasgupta S., Lall S. Wheeler D. Policy Reform, Economic Growth and the Digital Di- 
vide: An Econometric Analysis // Policy Research Working Paper №2567 // Washington: The World Bank Development Research Group infrastructure and Environment. - 2001. - 24 p.

5. Emrouznejad A., Cabanda E., Gholami R. An alternative measure of the ICT-Opportunity Index // Information and Management. 2010. — №47 (4). — Pp. 246-254.

6. Hunnius $S$. Stand und Perspektiven der Digitalisierung der Verwaltung // Digitale Transformation der Verwaltung. Empfehlungen fur eine desamtstaatliche Strategie. - Gutersloh: Bertelsmann. Stiftung, 2017. - Pp. 12-16.

7. Martini M. Digitalisierung als Herausforderung und Chance fur Staat und Verwaltung. Forschungskonzept des Programmbereichs «Transformation des Staates in Zeiten der Digitalisierung». - Speyer, 2016. - $119 \mathrm{p}$.

8. Pohjola M. The adoption and diffusion of ICT across countries: Patterns and determinants// The New Economy Handbook. - San Diego: Academic Press, 2003. - Pp. 77-100.

9. Stocksmeier D. Potenziale der digitalen Transformation fur die deutsche Verwaltung // Digitale Transformation der Verwaltung. Empfehlungen fur eine gesamtstaatlishe Strategie. Gutersloh: Bertelsmann Stiftung, 2017. Pp. 10-11.

10. Айснер Л. Ю., Наумов О.Д. Использование цифровых технологий при планировании, мониторинге и оценке государственного управления: анализ зарубежной практики // II Международная межвузовская научно-практическая конференция «Высокотехнологичное право: генезис и перспективы». - Красноярск, 2021. - С. 12-15.

11. Архипова М. Ю., Сиротин В.П. Региональные аспекты развития информационнокоммуникационных и цифровых технологий в России // Экономика региона. - 2019. T. 15. - Вып. 3. - С. 670-683.

12. Веретенникова А. Ю., Козинская К. М. Влияние цифровой трансформации неформальной институциональной среды на социальное предпринимательство с учетом концепции жизненного цикла // Журнал экономической теории. - 2020. - Т. 17. - №4. C. 932-943.

13. Гармаева Е.Р. Развитие инновационной инфраструктуры Санкт-Петербурга в условиях цифровизации // Цифровая экономика, умные инновации и технологии: сборник трудов национальной (Всероссийской) науч.практ. конф. с зарубежным участием. 2021. - C. 185-187.

14. Гретченко А.А., Деменко О.Г., Савина Н.П. Оценка готовности экономики России к внедрению цифровых технологий// Плехановский научный бюллетень. 2018. - №2 (14). - С. 14-20.

15. Данилова И.В., Савельева И. П., Лаnо A.C. Оценка стратегической социально-экономической политики региона: методический подход // Вестник ЮУрГУ. Серия: Экономика и менеджмент. - 2019. T. 13. 一 №2. - С. 17-27.

16. Дорошенко Ю.А., Мальхина И.О., Сомина И. В. Инновационное развитие региона в условиях современных трендов неоиндустриализации // Экономика региона. - 2020. T. 16. - Вып. 4. - С. 1318-1334.

17. Дубровский В.Ж., Орлова Т.С., Ярошевич Н. Ю. Формирование конкурентной среды в инфраструктурных отраслях с естественно-монопольной компонентой // Управленец. — 2014. — №6 (52). - С. 30-33.

18. Жукова М.А. Цифровые технологии и платформы как инструмент цифровой трансформации // Финансовый вестник. 2018. — №4 (43). — С. 84-88.

19. Калина А. М., Куликов М.М. Перспективы использования цифровых технологий на промышленных предприятиях Ростовской области // Вестник ЮРГТУ (НПИ). 2021. - №1. - С. 140-149.

20. Миронова О.В., Гладких С.Д., Канавнин E. A. Проблемы нормативного регулирования цифровой экономики и перспективы его развития в России // Всероссийская научно-практическая конференция «Проблемы российской экономики на современном этапе». - М., 2019. - С. 150-156.

21. Норалиев Н.Х., Юсупова Ф. Э. Цифровые технологии в сельском хозяйстве // Вопросы науки и образования. - 2020. №8 (92). - C. 4-10.

22. Полина Е.А., Соловьева И.А. Инструментарий комплексного анализа инновационного развития региона // Вестник ЮУрГУ. Серия: Экономика и менеджмент. - 2020. T. 14. - №2. - С. 37-45.

23. Рожков Е.В. Дубровский В.Ж. Роль и задачи цифровизации управления муниципальной собственностью // Урал - Драй- 
вер неоиндустриального и индустриального развития России. Материалы II Уральского экономического форума (Екатеринбург, 21-22 октября 2020 г.). - УрГЭУ, 2020. C. $116-122$.

24. Свиридова В.В. Мониторинг внедрения цифровых технологий в экономическую и социальную сферы регионов // Modern Science. - 2020. - №8-2. - C. 316-320.

25. Сибиряев А. С., Зазимко В.Л., Додов Р.Х. Цифровая трансформация и цифровые платформы в сельском хозяйстве // Вестник НГИЭИ. - 2020. - №12 (115). - С. 96-108.

26. Сидоренко Э.Л., Баричи И.Н., Хисамова З. И. Эффективность цифрового государственного управления: теоретические и прикладные аспекты // Вопросы государственного и муниципального управления. 2019. — №2. - С. 93-114.

27. Симонова В.Л., Одинаматов А. А., Протыняк Р.P. Тренды цифровой трансформации бизнеса в условиях долевой экономики// Журнал экономической теории. - 2020. T. 17. - №2. - С. 514-518.

28. Уланова О. И. Инновации как приоритетный элемент развития экономики России// VI Международная научно-практическая конференция «Формирование конкурентной среды, конкурентоспособность и стратегическое управление предприятиями, организациями и регионами». - Пенза, 2021. - С. 230-234.

29. Урасова А.А., Баландин Д.А. Теоретические и практические аспекты пространственно-отраслевого развития региона в условиях цифровизации // Вестник Астраханского государственного технического университета. Серия: Экономика. — 2021. - №1. - С. 3239. - DOI: 10.24143/2073-5537-2021-1-32-39.

30. Чарыкова О.Г., Маркова Е.С. Региональная кластеризация в цифровой экономике // Экономика региона. - 2019. - Т. 15. Вып. 2. - С. 409-419.

31. Чэнь Л. Проблемы и тенденции развития цифровой экономики // Цифровая экономика, умные инновации и технологии: сборник трудов Национальной (Всероссийской) науч.-практ. конф. с зарубежным участием. - Санкт-Петербург, 2021. - С. 108-111.

32. Южаков В. Н., Талапина Э.В., Ефремов A. . Правовые ограничения для использования прорывных цифровых технологий в государственном управлении // Вестник
РУДН. Серия: Политология. - 2018. №3. - С. 235-237.

\section{References}

1. Bagchi K. Factors contributing to Global Digital Divide: Some empirical results // Journal of Global information Technology Management. - 2005. - №8 (3). - Pp. 47-65.

2. Billon M., Marco R., Lera-Lopez F. Disparities in ICT adoption: A multidimensional approach to study the cross-country digital // Telecommunications Policy. - 2019. - №33(1011). - Pp. 596-610.

3. Chinn M.D., Fairlie R.W. The Determinants of the Global Digital Divide: A CrossCountry Analysis of Computer and Internet Penetration // Oxford Economic Papers. New Series. - 2007. — Vol. 59. — №1. - Pp. 16-44.

4. Dasgupta S., Lall S. Wheeler D. Policy Reform, Economic Growth and the Digital Divide: An Econometric Analysis // Policy Research Working Paper №2567 // Washington: The World Bank Development Research Group infrastructure and Environment. - 2001. - 24 p.

5. Emrouznejad A., Cabanda E., Gholami R. An alternative measure of the ICT-Opportunity Index // Information and Management. 2010. — №47 (4). — Pp. 246-254.

6. Hunnius $S$. Stand und Perspektiven der Digitalisierung der Verwaltung // Digitale Transformation der Verwaltung. Empfehlungen fur eine desamtstaatliche Strategie. - Gutersloh: Bertelsmann. Stiftung, 2017. - Pp. 12-16.

7. Martini M. Digitalisierung als Herausforderung und Chance fur Staat und Verwaltung. Forschungskonzept des Programmbereichs «Transformation des Staates in Zeiten der Digitalisierung». - Speyer, 2016. - 119 p.

8. Pohjola $M$. The adoption and diffusion of ICT across countries: Patterns and determinants// The New Economy Handbook. - San Diego: Academic Press, 2003. - Pp. 77-100.

9. Stocksmeier D. Potenziale der digitalen Transformation fur die deutsche Verwaltung // Digitale Transformation der Verwaltung. Empfehlungen fur eine gesamtstaatlishe Strategie. Gutersloh: Bertelsmann Stiftung, 2017. Pp. 10-11.

10. Ajsner L. Ju., Naumov O. D. Ispol'zovanie cifrovyh tehnologij pri planirovanii, monitoringe i ocenke gosudarstvennogo upravlenija: analiz 
zarubezhnoj praktiki [The use of digital technologies in planning, monitoring and evaluation of public administration: an analysis of foreign practice] // II Mezhdunarodnaja mezhvuzovskaja nauchno-prakticheskaja konferencija «Vysokotehnologichnoe pravo: genezis i perspektivy» [II International interuniversity scientific and practical conference «High-tech law: genesis and prospects»]. - Krasnojarsk, 2021. - Pp. 12-15.

11. Arhipova M. Ju., Sirotin V.P. Regional'nye aspekty razvitija informacionno-kommunikacionnyh i cifrovyh tehnologij v Rossii [Regional aspects of the development of information and communication and digital technologies in Russia] // Jekonomika regiona [The economy of the region]. - 2019. - Vol. 15. - Issue 3. Pp. 670-683.

12. Veretennikova A. Ju., Kozinskaja K.M. Vlijanie cifrovoj transformacii neformal'noj institucional'noj sredy na social'noe predprinimatel'stvo s uchetom koncepcii zhiznennogo cikla [The influence of the digital transformation of the informal institutional environment on social entrepreneurship taking into account the concept of the life cycle] // Zhurnal jekonomicheskoj teorii [Journal of Economic Theory]. 2020. - Vol. 17. — №4. - Pp. 932-943.

13. Garmaeva E.R. Razvitie innovacionnoj infrastruktury Sankt-Peterburga v uslovijah cifrovizacii [Development of the innovative infrastructure of St. Petersburg in the conditions of digitalization] // Cifrovaja jekonomika, umnye innovacii i tehnologii: sbornik trudov nacional'noj (Vserossijskoj) nauch.-prakt. konf. s zarubezhnym uchastiem [Digital economy, smart innovations and technologies: proceedings of the national (All-Russian) scientific and practical conference with foreign participation]. 2021. - Pp. 185-187.

14. Gretchenko A.A., Demenko O.G., Savina N.P. Ocenka gotovnosti jekonomiki Rossii $\mathrm{k}$ vnedreniju cifrovyh tehnologij [Assessment of the readiness of the Russian economy for the introduction of digital technologies] // Plehanovskij nauchnyj bjulleten' [Plekhanov Scientific Bulletin]. - 2018. — №2 (14). — Pp. 14-20.

15. Danilova I. V., Savel'eva I. P., Lapo A.S. Ocenka strategicheskoj social'no-jekonomicheskoj politiki regiona: metodicheskij podhod [Evaluation of the strategic socio-economic policy of the region: a methodological approach] // Vestnik JuUrGU. Serija: Jekonomika i menedzh- ment [Bulletin of SUSU. Series: Economics and Management]. - 2019. - Vol. 13. - №2. Pp. 17-27.

16. Doroshenko Ju. A., Malyhina I.O., Somina $I$. $V$. Innovacionnoe razvitie regiona $\mathrm{v}$ uslovijah sovremennyh trendov neoindustrializacii [Innovative development of the region in the conditions of modern trends of neo-industrialization] // Jekonomika regiona [The economy of the region]. - 2020. — Vol. 16. - Issue 4. Pp. 1318-1334.

17. Dubrovskij V. Zh., Orlova T.S., Jaroshevich $N$. Ju. Formirovanie konkurentnoj sredy $\mathrm{v}$ infrastrukturnyh otrasljah s estestvennomonopol'noj komponentoj [Creating a specific environment in infrastructure industries with natural monopoly component] // Upravlenec [Manager]. - 2014. — №6 (52). - Pp. 30-33.

18. Zhukova M.A. Cifrovye tehnologii i platformy kak instrument cifrovoj transformacii [Digital technologies and platform as a tool for digital transformation] // Finansovyj vestnik [The Financial Gazette]. — 2018. №4 (43). - Pp. 84-88.

19. Kalina A.M., Kulikov M.M. Perspektivy ispol'zovanija cifrovyh tehnologij na promyshlennyh predprijatijah Rostovskoj oblasti [Prospects for the use of digital technologies in industrial enterprises of the Rostov region] // Vestnik JuRGTU (NPI) [Bulletin of the SRSPU (NPI)]. - 2021. — №1. - Pp. 140-149.

20. Mironova O.V., Gladkih S.D., Kanavnin E.A. Problemy normativnogo regulirovanija cifrovoj jekonomiki i perspektivy ego razvitija $\mathrm{v}$ Rossii [Problems of regulation of the digital economy and the prospects of its development in Russia] // Vserossijskaja nauchno-prakticheskaja konferencija «Problemy rossijskoj jekonomiki na sovremennom jetape» [All-Russian scientific-practical conference «Problems of the Russian economy at the present stage»]. - Moscow, 2019. - Pp. 150-156.

21. Noraliev N. H., Jusupova F. Je. Cifrovye tehnologii v sel'skom hozjajstve [Digital technology in agriculture] // Voprosy nauki i obrazovanija [Issues of science and education]. 2020. 一 №8 (92). - Pp. 4-10.

22. Polina E.A., Solov'eva I.A. Instrumentarij kompleksnogo analiza innovacionnogo razvitija regiona [Tools for complex analysis of innovative development of the region] // Vestnik JuUrGU. Serija: Jekonomika i menedzh- 
ment [Bulletin of SUSU. Series: Economics and Management]. — 2020. — Vol. 14. — №2. Pp. 37-45.

23. Rozhkov E. V. Dubrovskij V. Zh. Rol' i zadachi cifrovizacii upravlenija municipal'noj sobstvennost'ju [The role and tasks of digitalization of municipal property management] // Ural - Drajver neoindustrial'nogo i industrial'nogo razvitija Rossii. Materialy II Ural'skogo jekonomicheskogo foruma (Ekaterinburg, 21-22 oktjabrja 2020 g.) [Ural - Driver of neo-industrial and industrial development of Russia. Materials of the II Ural Economic Forum (Yekaterinburg, October 21-22, 2020)]. UrGJeU, 2020. - Pp. 116-122.

24. Sviridova V.V. Monitoring vnedrenija cifrovyh tehnologij $\mathrm{v}$ jekonomicheskuju i social'nuju sfery regionov [Monitoring the introduction of digital technologies in the economic and social spheres of the regions] // Modern Science. - 2020. - №8-2. - Pp. 316-320.

25. Sibirjaev A.S., Zazimko V.L., Dodov R. H. Cifrovaja transformacija i cifrovye platformy $\mathrm{v}$ sel'skom hozjajstve [Digital transformation and digital platforms in agriculture]// Vestnik NGIJeI. — 2020. — №12 (115). — Pp. 96-108.

26. Sidorenko Je. L., Barcic I.N., Hisamova Z.I. Jeffektivnost' cifrovogo gosudarstvennogo upravlenija: teoreticheskie i prikladnye aspekty [The effectiveness of digital public administration: theoretical and applied aspects] // Voprosy gosudarstvennogo i municipal'nogo upravlenija [Issues of state and municipal management]. — 2019. — №2. - Pp. 93-114.

27. Simonova V.L., Odinamatov A.A., Protynjak $R$. $R$. Trendy cifrovoj transformacii biznesa $\mathrm{v}$ uslovijah dolevoj jekonomiki [Trends of digital transformation of business in the conditions of shared economy] // Zhurnal jekonomicheskoj teorii [Journal of Economic Theory]. 2020. - Vol. 17. — №2. - Pp. 514-518.

28. Ulanova O.I. Innovacii kak prioritetnyj jelement razvitija jekonomiki Rossii [Innovations as a priority element of the development of the Russian economy] // VI Mezhdunar- odnaja nauchno-prakticheskaja konferencija «Formirovanie konkurentnoj sredy, konkurentosposobnost' i strategicheskoe upravlenie predprijatijami, organizacijami i regionami» [VI International Scientific and practical Conference «Formation of a competitive environment, competitiveness and strategic management of enterprises, organizations and regions»]. - Penza, 2021. - Pp. 230-234.

29. Urasova A.A., Balandin D.A. Teoreticheskie i prakticheskie aspekty prostranstvenno-otraslevogo razvitija regiona $\mathrm{v}$ uslovijah cifrovizacii [Theoretical and practical aspects of the spatial and sectoral development of the region in the conditions of digitalization] // Vestnik Astrahanskogo gosudarstvennogo tehnicheskogo universiteta. Serija: Jekonomika [Bulletin of the Astrakhan State Technical University. Series: Economics]. — 2021. — №1. — Pp. 32-39. DOI: 10.24143/2073-5537-2021-1-32-39.

30. Charykova O.G., Markova E.S. Regional'-naja klasterizacija $\mathrm{v}$ cifrovoj jekonomike [Regional clustering in the digital economy] // Jekonomika regiona [The economy of the region]. - 2019. - Vol. 15. - Issue 2. Pp.409-419.

31. Chjen' L. Problemy i tendencii razvitija cifrovoj jekonomiki [Problems and trends in the development of the digital economy] // Cifrovaja jekonomika, umnye innovacii i tehnologii: sbornik trudov Nacional'noj (Vserossijskoj) nauch.-prakt. konf. s zarubezhnym uchastiem [Digital economy, smart innovations and technologies: proceedings of the National (AllRussian) Scientific and Practical Conference with foreign participation]. - Saint Petersburg, 2021. - Pp. 108-111.

32.Juzhakov V.N., Talapina Je. V., Efremov A.A. Pravovye ogranichenija dlja ispol'zovanija proryvnyh cifrovyh tehnologij $\mathrm{v}$ gosudarstvennom upravlenii [Legal restrictions for the use of breakthrough digital technologies in public administration] // Vestnik RUDN. Serija: Politologija [Vestnik RUDN. Series: Political Science]. — 2018. — №3. - Pp. 235-237. 


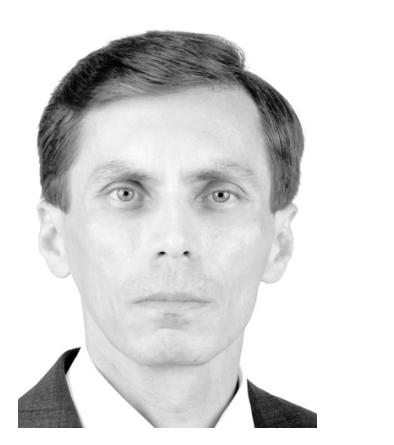

Рожков Евгений Викторович - аспирант кафедры Экономики предприятий Уральского государственного экономического университета.

Rozhkov Evgeny Viktorovich - Postgraduate Student of the Department of Enterprise Economics, Ural State University of Economics.

620144 , г. Екатеринбург, ул. 8 Марта / Народной Воли, 62/45 62/45, 8 Marta / Narodnoy Voli st., 620144, Ekaterinburg, Russia E-mail: erozhkov00@bk.ru 